Article

\title{
Preparation of Microparticles Capable of Glucose-Induced Insulin Release under Physiological Conditions
}

\author{
Kentaro Yoshida ${ }^{1, *}$, Kazuma Awaji ${ }^{2}$, Seira Shimizu ${ }^{2}$, Miku Iwasaki ${ }^{2}$, Yuki Oide ${ }^{2}$, \\ Megumi Ito ${ }^{2}$, Takenori Dairaku ${ }^{1}$, Tetsuya Ono ${ }^{1}$, Yoshitomo Kashiwagi ${ }^{1}$ and Katsuhiko Sato ${ }^{2}$ \\ 1 School of Pharmaceutical Sciences, Ohu University 31-1 Misumido, Tomita-Machi, Koriyama, \\ Fukushima 963-8611, Japan; t-dairaku@pha.ohu-u.ac.jp (T.D.); t-ono@pha.ohu-u.ac.jp (T.O.); \\ y-kashiwagi@pha.ohu-u.ac.jp (Y.K.) \\ 2 Graduate School of Pharmaceutical Sciences, Tohoku University, 6-3 Aoba, Aramaki, Aoba-ku, \\ Sendai 980-8578, Japan; sabapena3@yahoo.co.jp (K.A.); simizuseira@gmail.com (S.S.); \\ ilax84@gmail.com (M.I.); cyluaurkiinet@gmail.com (Y.O.); migumeito@gmail.com (M.I.); \\ satok@m.tohoku.ac.jp (K.S.) \\ * Correspondence: k-yoshida@pha.ohu-u.ac.jp; Tel.: +81-24-932-8931; Fax: +81-24-933-7372
}

Received: 25 September 2018; Accepted: 17 October 2018; Published: 18 October 2018

\begin{abstract}
Hydrogen peroxide $\left(\mathrm{H}_{2} \mathrm{O}_{2}\right)$-sensitive layer-by-layer films were prepared based on combining phenyl boronic acid (PBA)-modified poly(allylamine) (PAH) with shikimic acid (SA)-modified-PAH through boronate ester bonds. These PBA-PAH/SA-PAH multilayer films could be prepared in aqueous solutions at $\mathrm{pH} 7.4$ and 9.0 in the presence of $\mathrm{NaCl}$. It is believed that the electrostatic repulsion between the SA-PAH and PBA-PAH was diminished and the formation of ester bonds between the SA and PBA was promoted in the presence of $\mathrm{NaCl}$. These films readily decomposed in the presence of $\mathrm{H}_{2} \mathrm{O}_{2}$ because the boronate ester bonds were cleaved by an oxidation reaction. In addition, SA-PAH/PBA-PAH multilayer films combined with glucose oxidase (GOx) were decomposed in the presence of glucose because GOx catalyzes the oxidation of D-glucose to generate $\mathrm{H}_{2} \mathrm{O}_{2}$. The surfaces of $\mathrm{CaCO}_{3}$ microparticles were coated with PAH/GOx/(SA-PAH/PBA-PAH) 5 films that absorbed insulin. A $1 \mathrm{mg}$ quantity of these particles released up to $10 \mu \mathrm{g}$ insulin in the presence $10 \mathrm{mM}$ glucose under physiological conditions.
\end{abstract}

Keywords: phenyl boronic acid; hydrogen peroxide; drug delivery system; insulin; LbL film; glucose response

\section{Introduction}

Stimuli-sensitive drug release devices such as microchips [1], gels [2,3] and microcapsules [4,5] have been widely studied with regard to biomedical applications. Glucose-sensitive insulin release has attracted particular attention, since the development of insulin delivery systems for the self-regulation of blood glucose levels would be helpful for diabetes mellitus patients. Glucose-sensitive materials such as lectins [6], glucose oxidase [7,8] and phenyl boronic acid (PBA) [9-11] have been employed for this purpose. Because the glucose-sensitive release of insulin could mimic the function of the pancreas, this technology might eliminate repetitive insulin injections.

Layer-by-layer (LbL) multilayer films can be prepared by the alternating and repeated deposition of polymeric materials on the surface of a solid substrate [12]. The polymers are deposited on the substrate by attractive forces that include electrostatic interaction [13-15], hydrogen bonds [16,17], avidin-biotin binding [18] and sugar-lectin binding [19]. Thus, both synthetic polymers and biological materials can be used to produce LbL films, with applications in sensors [20,21], separation and 
purification [22,23], microcapsules [24-26], drug delivery systems (DDSs) [27-29] and stimuli-sensitive devices $[30,31]$. There have been many studies devoted to stimuli-sensitive LbL films that decompose in response to environmental stimuli such as $\mathrm{pH}$ [32], ionic strength [33], biological molecules [34] and electrical signals [35]. If such films can incorporate glucose-sensitive materials, a release process based on physiological conditions could be realized. Therefore, it has been suggested that glucose-sensitive multilayer films could be used to develop insulin delivery systems.

Our own groups have previously developed $\mathrm{pH}$ - and sugar-sensitive LbL films composed of PBA-modified poly(allylamine hydrochloride) (PBA-PAH) and poly(vinyl alcohol) (PVA) [36]. PBA derivatives are of particular interest because they selectively bind 1,2- and 1,3-diol compounds such as sugars [37,38]; Figure 1 shows the binding of a diol compound to a boronate ester. For this reason, the use of PBA derivatives in the development of sugar-sensitive drug delivery systems has been suggested [39-42]. It is difficult to decompose these PBA-PAH/PVA LbL films under physiological conditions, but PBA and boronate esters are sensitive to reactive oxygen species (ROS). As an example, these compounds can be irreversibly decomposed as the result of the oxidative scission of the carbon-boron bond by hydrogen peroxide $\left(\mathrm{H}_{2} \mathrm{O}_{2}\right)$ [43]. We have previously reported the $\mathrm{H}_{2} \mathrm{O}_{2}$-induced decomposition of LbL films consisting of PBA-PAH and PVA [44], as well as the glucose-induced decomposition of multilayer PBA-PAH/PVA films by glucose oxidase (GOx) [45].

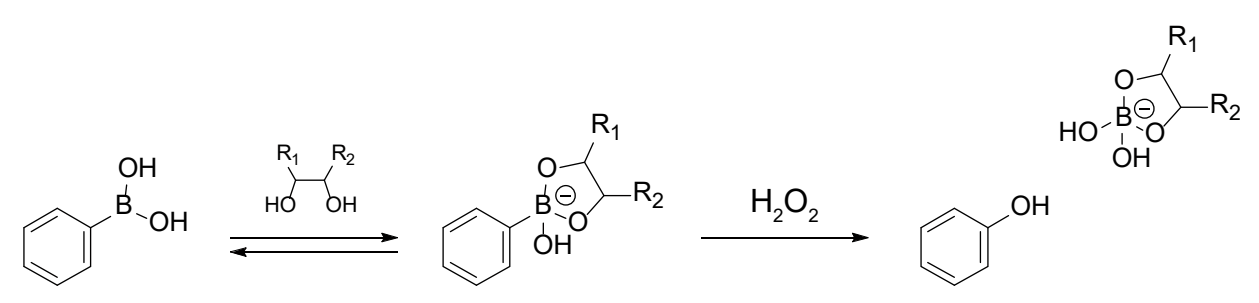

Figure 1. Sequential equilibrium and oxidation reactions of phenyl boronic acid with a diol and $\mathrm{H}_{2} \mathrm{O}_{2}$, respectively.

Microparticles coated with LbL films are extremely useful in DDS applications, although such materials made with PBA-PAH/PVA multilayer films have a tendency to aggregate. In the present work, LbL films capable of undergoing $\mathrm{H}_{2} \mathrm{O}_{2}$ - and glucose-induced decomposition were applied as coatings to fine particles, with the aim of developing a system for glucose-induced insulin release under physiological conditions (Figure 2)

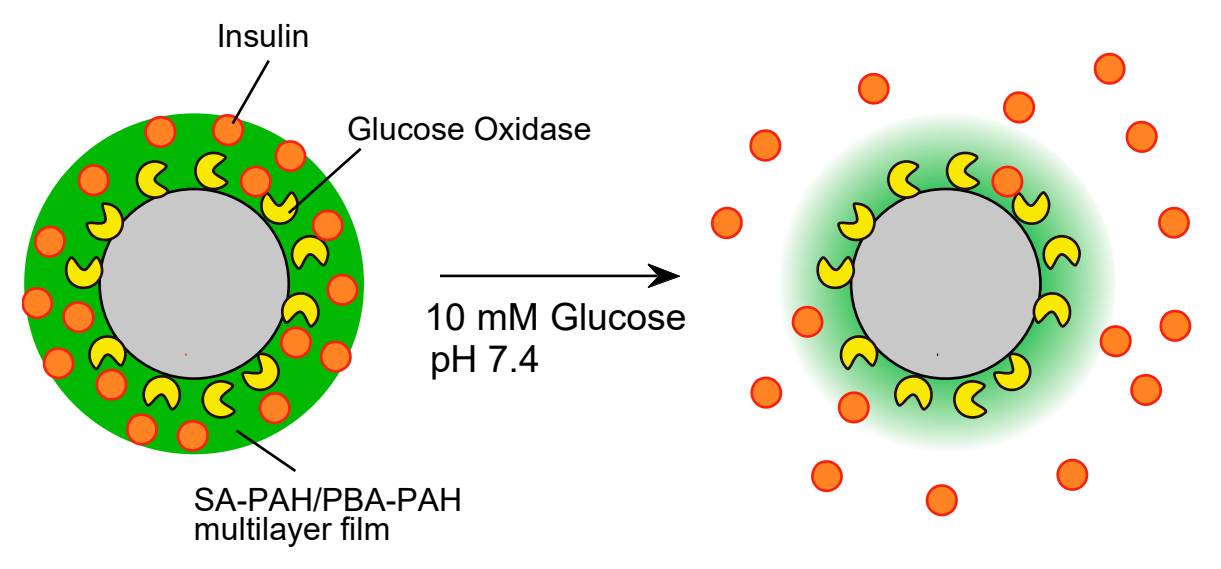

Figure 2. A schematic illustration of the functioning of a glucose-induced insulin release microparticle. 


\section{Experimental}

\subsection{Materials}

PAH (molecular weight: 150,000) and insulin (human, recombinant) were obtained from Nittobo Co. (Tokyo, Japan) and Wako Pure Chemical Ind. (Osaka, Japan), respectively. GOx (activity: 100 units $\mathrm{mg}^{-1}$ solid) was obtained from Toyobo Co., Ltd. (Osaka, Japan) and $\mathrm{H}_{2} \mathrm{O}_{2}$ (30\% aqueous solution) was obtained from Santoku Chemical Industries Co., Ltd. (Tokyo, Japan). Shikimic acid (SA), 4-carboxyphenyl boronic acid and 4-( $N, N$-dimethylaminosulfonyl)-7(2-aminoethylamino)-2,1,3-benzoxadiazole (DBD-ED) were purchased from Tokyo Chemical Industry Co., Ltd. (Tokyo, Japan) while 1-ethyl-3-(3-dimethylaminopropyl)carbodiimide hydrochloride (EDC) and N-hydroxysuccinimide (NHS) were obtained from Nacalai Tesque Co. (Kyoto, Japan). All other reagents were of the highest possible grade and were used as received without further purification.

PBA-PAH was synthesized according to a literature procedure [36]. The PAH contained approximately 15\% PBA residues (based on the molar ratio of PBA to primary amine groups) as calculated from the proportions of nitrogen and carbon determined by elemental analysis. The calculated elemental composition of the PBA-PAH was $\mathrm{C}=39.99 \%, \mathrm{H}=7.55 \%$ and $\mathrm{N}=11.53 \%$, and the experimental results showed $\mathrm{C}=42.29 \%, \mathrm{H}=6.2 \%$ and $\mathrm{N}=11.42 \%$.

SA-modified PAH (SA-PAH) was synthesized by reacting SA and PAH in water in the presence of NHS and EDC. In this process, EDC (109 mg) was added to a solution of SA (100 mg), PAH $(100 \mathrm{mg})$ and NHS $(66 \mathrm{mg})$ in water $(30 \mathrm{~mL})$ and the reaction mixture was stirred for $1 \mathrm{~h}$ at $0{ }^{\circ} \mathrm{C}$ and then for $12 \mathrm{~h}$ at room temperature. The resulting SA-PAH was purified by dialysis in water using a dialysis membrane (molecular weight cut-off of 12,000-14,000, Fast Gene, Nippon Genetics). The PAH contained approximately $26 \%$ SA residues (based on the molar ratio of SA to primary amine groups) as calculated from the proportions of nitrogen and carbon determined by elemental analysis. The calculated elemental composition of the SA-PAH was $\mathrm{C}=47.00 \%, \mathrm{H}=7.81 \%$ and $\mathrm{N}=11.32 \%$. The C / N ratio based on these data is 4.15 , and so SA-PAH bearing $26 \%$ SA was obtained.

DBD-labeled insulin (DBD-insulin) was synthesized by reacting DBD-ED and insulin in water in the presence of NHS and EDC. EDC $(3.30 \mathrm{mg})$ was added to a solution of DBD-ED $(4.91 \mathrm{mg})$ in a mixture of DMF $(0.5 \mathrm{~mL})$, insulin $(100 \mathrm{mg})$ and NHS $(1.98 \mathrm{mg})$ in water. The reaction mixture was stirred for $1 \mathrm{~h}$ at $0{ }^{\circ} \mathrm{C}$ and then for $12 \mathrm{~h}$ at room temperature. The resulting DBD-insulin was purified by dialysis in water using a dialysis membrane, after which it was freeze-dried. The chemical structures of the PBA-PAH, SA-PAH and DBD-ED are shown in Figure 3.<smiles>CCC(CC)CN</smiles>

$\mathrm{PAH}$

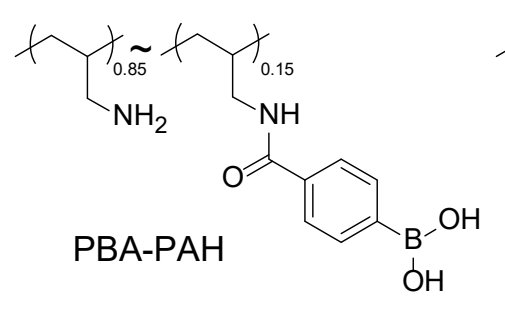
$\mathrm{OH}$

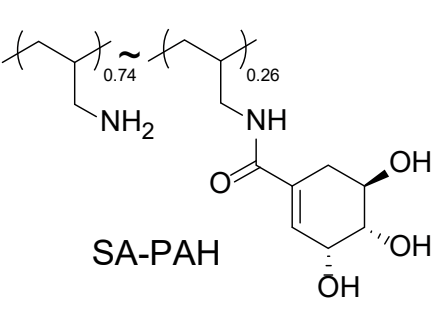

DBD-ED

Figure 3. The chemical structures of the PAH, PBA-PAH, SA-PAH and DBD-ED.

\subsection{Apparatus}

A quartz crystal microbalance (QCM, QCA 917 system, Seiko EG \& G, Tokyo, Japan) and a flow cell were used for gravimetric analysis of the LbL films. A $9 \mathrm{MHz}$ AT-cut quartz resonator coated with a thin Au layer (surface area: $0.2 \mathrm{~cm}^{2}$ ) was used as a probe, such that the adsorption of $1 \mathrm{ng}$ of a substance induced $\mathrm{a}-0.91 \mathrm{~Hz}$ change in the resonance frequency. UV-vis and fluorescence spectra were acquired using a 3100PC spectrophotometer (Shimadzu, Kyoto, Japan) and an FP-6500 fluorescence 
spectrophotometer (JASCO, Tokyo, Japan), respectively. Optical microscopy and fluorescence microscopy images were obtained with an LSM510 instrument (ZEISS, Oberkochen, Germany).

\subsection{Preparation of $S A-P A H / P B A-P A H$ Multilayer Films}

SA-PAH/PBA-PAH multilayer films were prepared on solid substrates. Each substrate was initially immersed in an SA-PAH solution $(0.1 \mathrm{mg} / \mathrm{mL})$ for $15 \mathrm{~min}$ to deposit the first SA-PAH layer. After rinsing in a working buffer for $5 \mathrm{~min}$ to remove any weakly adsorbed SA-PAH, the substrate was immersed in a PBA-PHA solution $(0.1 \mathrm{mg} / \mathrm{mL})$ for $15 \mathrm{~min}$ to deposit PBA-PHA. The second SA-PAH and PBA-PHA layers were deposited using the same technique and this deposition process was repeated to build an (SA-PAH/PBA-PAH) 10 multilayer film. The working buffers consisted of $10 \mathrm{mM}$ 2-( $N$-morpholino)ethanesulfonic acid (MES) buffer ( $\mathrm{pH}$ 5.0), $10 \mathrm{mM}$ 4-(2-hydroxyethyl)-1-piperazineethanesulfonic acid (HEPES) buffer (pH 7.4) or $10 \mathrm{mM}$ $\mathrm{N}$-Cyclohexyl-2-aminoethanesulfonic acid (CHES) buffer ( $\mathrm{pH}$ 9.0). The effect of ionic strength on the SA-PAH/PBA-PAH multilayer films was investigated by adding $\mathrm{NaCl}$ to the buffers.

SA-PAH/PBA-PAH films containing GOx was prepared by building (SA-PAH/PBA-PAH) 10 multilayer films on $\mathrm{PAH} / \mathrm{GOx}$ films at ambient temperature (approximately $20^{\circ} \mathrm{C}$ ). A solid substrate was coated in advance with a PAH/GOx film by immersing the slide alternately in $0.1 \mathrm{mg} \mathrm{mL}^{-1}$ PAH and $0.1 \mathrm{mg} \mathrm{mL}^{-1} \mathrm{GOx}$ solutions [39]. The glucose response was studied in a series of $10 \mathrm{mM}$ HEPES buffers (pH 7.4, $150 \mathrm{mM}$ or $1 \mathrm{M} \mathrm{NaCl}$ ) and $10 \mathrm{mM} \mathrm{CHES} \mathrm{buffer} \mathrm{(pH} \mathrm{9.0,1} \mathrm{M} \mathrm{NaCl).} \mathrm{A} 9 \mathrm{MHz}$ Au-coated quartz resonator and a quartz slide $(4.5 \times 0.9 \times 0.1 \mathrm{~cm})$ were used for QCM analysis and UV-vis absorption measurements, respectively.

\section{4. $\mathrm{H}_{2} \mathrm{O}_{2}$ - and Glucose-Induced Decomposition of LbL Films}

The $\mathrm{H}_{2} \mathrm{O}_{2}$ - and glucose-induced decompositions of various films were studied by UV-vis absorption spectroscopy. To determine the kinetics of film decomposition, one side of a quartz slide was coated with an LbL film and the slide was placed in a quartz cuvette (optical path length: $10 \mathrm{~mm}$ ) filled with a buffer solution. The slide was placed near the sidewall of the cuvette, parallel to the light path, in order to avoid blocking the incident light. The absorbance of the solution at $255 \mathrm{~nm}$ was monitored with gentle stirring of the buffer to estimate the extent of film decomposition at different $\mathrm{pH}$ values in the absence and presence of $\mathrm{H}_{2} \mathrm{O}_{2}$ and glucose.

\subsection{Preparation of Microparticles Coated with SA-PAH/PBA-PAH Multilayer Films}

In this procedure, $10 \mathrm{~mL}$ of a $\mathrm{Ca}\left(\mathrm{NO}_{3}\right)_{2}(472 \mathrm{mg})$ solution was combined with $10 \mathrm{~mL}$ of a $\mathrm{Na}_{2} \mathrm{CO}_{3}$ $\left(210 \mathrm{mg}\right.$ ) solution and the mixture was stirred for $30 \mathrm{~min}$, after which the precipitated $\mathrm{CaCO}_{3}$ particles were collected by centrifugation and washed with water [46]. The surfaces of these particles was coated with multilayer films by immersing them alternately in $0.1 \mathrm{mg} / \mathrm{mL}$ SA-PAH and $0.1 \mathrm{mg} / \mathrm{mL}$ PBA-PAH solutions (both in a pH $9.010 \mathrm{mM}$ CHES buffer) for $15 \mathrm{~min}$. After each deposition, the $\mathrm{CaCO}_{3}$ particles were collected by centrifugation and rinsed in the working buffer for $5 \mathrm{~min}$. The alternating deposition of SA-PAH and PBA-PAH was repeated in this manner to prepare (SA-PAH/PBA-PAH) 5 multilayer films on the $\mathrm{CaCO}_{3}$ particles.

Glucose-sensitive microparticles coated with SA-PAH/PBA-PAH multilayer films were prepared by building (SA-PAH/PBA-PAH) $)_{5}$ multilayer films on PAH/GOx film-coated $\mathrm{CaCO}_{3}$ particles. The $\mathrm{CaCO}_{3}$ particles were initially coated with a PAH/GOx film by immersing them alternately in $0.1 \mathrm{mg} \mathrm{mL}^{-1} \mathrm{PAH}$ and $0.1 \mathrm{mg} \mathrm{mL}^{-1} \mathrm{GOx}$ solutions. Microparticles containing DBD-insulin were prepared using a PBA-PAH solution with $0.1 \mathrm{mg} / \mathrm{mL}$ DBD-insulin added. These glucose-sensitive films were prepared in a $10 \mathrm{mM}$ HEPES buffer $(\mathrm{pH} 7.4,150 \mathrm{mM} \mathrm{NaCl})$ and were freeze-dried after being prepared. 


\section{6. $\mathrm{H}_{2} \mathrm{O}_{2}$ - and Glucose-Induced Decomposition of Microparticles Coated with LbL Films}

$\mathrm{H}_{2} \mathrm{O}_{2}$-sensitive microparticles coated with SA-PAH/PBA-PAH multilayer films were assessed using UV-vis absorption spectroscopy (UV-3100PC, Shimazu Co., Kyoto, Japan). The freeze dried microparticles ( $20 \mathrm{mg}$ ) were immersed in solutions containing from 0.1 to $10 \mathrm{mM} \mathrm{H}_{2} \mathrm{O}_{2}$ and stirred. After a specific time period, the microparticles were removed by centrifugation and the supernatant was collected. The $\mathrm{H}_{2} \mathrm{O}_{2}$ in the supernatant was decomposed by adding $1.0 \mathrm{mg} / \mathrm{mL}$ catalase $(100 \mu \mathrm{L})$ and the absorbance of the supernatant at $255 \mathrm{~nm}$ was monitored to determine the amount of PBA in solution due to decomposition of the SA-PAH/PBA-PAH multilayer films.

The DBD-insulin release from glucose-sensitive PAH/GOx/(SA-PAH/PBA-PAH) $)_{5}$ film-coatedmicroparticles were studied by fluorescence emission spectroscopy. The freeze-dried microparticles $(10 \mathrm{mg})$ were immersed in solutions containing 1 to $100 \mathrm{mM}$ glucose and stirred for $60 \mathrm{~min}$. The microparticles were subsequently removed by centrifugation and the supernatant was collected. The supernatant was passed through a filter (pore size $0.45 \mu \mathrm{m}$, RC-membrane, Sartorius Stedim, Germany) and the fluorescence intensity of the filtrate was recorded at $505 \mathrm{~nm}$ (excitation: $488 \mathrm{~nm}$ ) to estimate the amount of DBD-insulin released.

\section{Results and Discussion}

\subsection{SA-PAH/PBA-PAH Multilayer Films Characterization}

In a previous study, we attempted to prepare $\mathrm{H}_{2} \mathrm{O}_{2}$ - and glucose-responsive multilayer films composed of microparticles coated with PBA-PAH and PVA [36]. However, microparticles coated with PBA-PAH/PVA multilayer films were found to aggregate. Multilayer films composed of PBA-PAH were found to accumulate positive charges, while the PVA films had low charge densities. Therefore, aggregation of the particles was attributed to a reduction in the repulsive force between them. In the present study, $\mathrm{H}_{2} \mathrm{O}_{2}$-responsive multilayer films composed of SA-PAH and PBA-PAH were prepared via the formation of boronate ester bonds between the boronic acid moieties in the PBA-PAH and the diol units in the SA. However, the deposition of SA-PAH/PBA-PAH multilayer films could potentially be hindered by the electrostatic repulsion between the SA-PAH and PBA-PAH. For this reason, increasing the ionic strength of the associated solutions was assessed as a means of promoting film formation. The effect of ionic strength (as reflected by changes in the $\mathrm{NaCl}$ concentration) during the preparation of SA-PAH/PBA-PAH multilayer films was investigated using QCM (Figure 4). Variations in the resonance frequency $(\triangle \mathrm{F})$ were monitored after rinsing with the working buffer, and $-\Delta \mathrm{F}$ was found to increase when the quartz resonator was exposed to the SA-PAH and PBA-PAH solutions in the presence of $\mathrm{NaCl}$, indicating that SA-PAH/PBA-PAH multilayer films were successfully formed on the surface of the quartz resonator. In contrast, SA-PAH/PBA-PAH multilayers could not be prepared in the absence of $\mathrm{NaCl}$. The deposition densities of the (SA-PAH/PBA-PAH) 10 film were calculated to be 2.80 and $5.45 \mu \mathrm{g} \mathrm{cm}^{-2}$ when using the $150 \mathrm{mM}$ and $1 \mathrm{M} \mathrm{NaCl}$ solutions, respectively. Thus, as expected, higher $\mathrm{NaCl}$ concentrations increased the amount of SA-PAH/PBA-PAH multilayer film that was deposited. This likely occurred because the electrostatic repulsion between the SA-PAH and PBA-PAH was diminished, promoting the formation of ester bonds between the shikimic and boronic acid moieties. A high ionic strength in the buffer also causes the polyelectrolyte to contract so as to increase the amount of polymer deposited per layer [47].

Figure 5 shows the UV-vis absorption spectra of SA-PAH/PBA-PAH multilayer films prepared on quartz slides. These spectra exhibit adsorption maxima at approximately $242 \mathrm{~nm}$, originating from the PBA units in the PBA-PAH. The intensity of these peaks increased with increasing number of depositions, suggesting that SA-PAH/PBA-PAH multilayer films were successfully prepared on the slides. In agreement with the QCM results, increasing the $\mathrm{NaCl}$ concentration of the solution increased the amount of PBA-PAH deposited. 


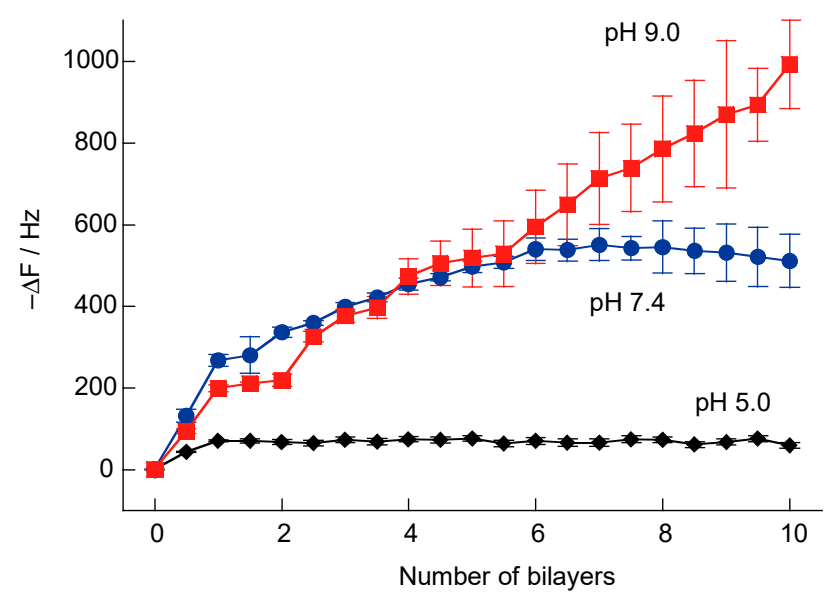

Figure 4. QCM resonator frequency changes during the preparation of (SA-PAH/PBA-PAH) $)_{n}$ films in a $10 \mathrm{mM}$ CHES buffer ( $\mathrm{pH}$ 9.0) in the presence and absence of $\mathrm{NaCl}(150 \mathrm{mM}$ or $1 \mathrm{M})$.
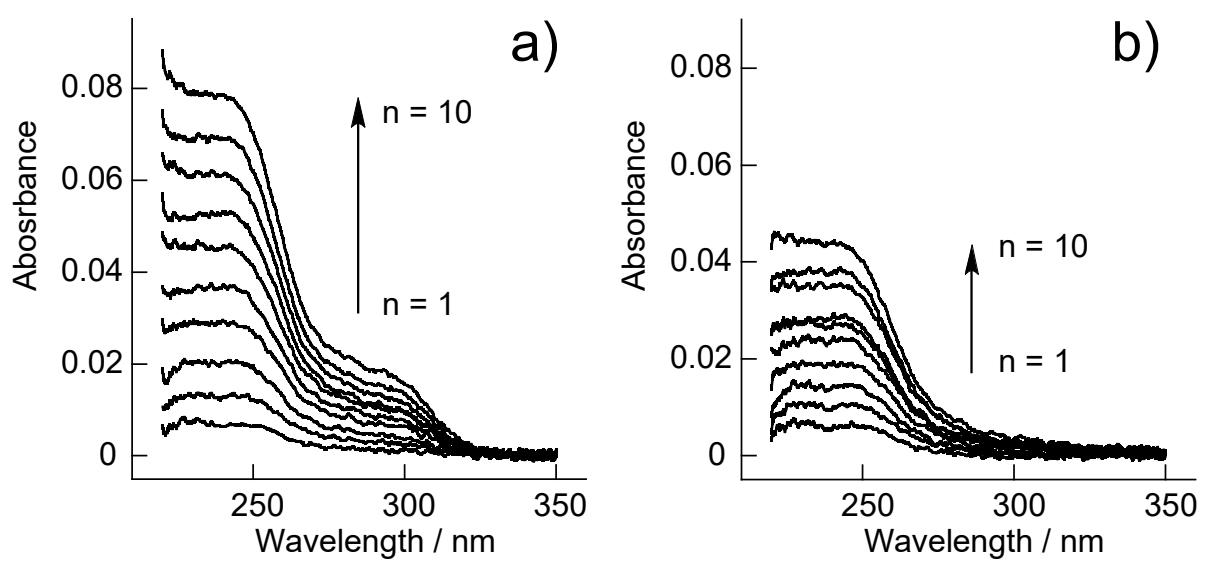

Figure 5. UV-vis absorption spectra during the preparation of (SA-PAH/PBA-PAH) films in a $10 \mathrm{mM}$ CHES buffer ( $\mathrm{pH} 9.0$ ) in the presence of $1 \mathrm{M} \mathrm{NaCl}(\mathbf{a})$ or $150 \mathrm{mM} \mathrm{NaCl}(\mathbf{b})$.

The bonding of PBA to diols is known to be unstable at neutral and acidic $\mathrm{pH}$ values [31,32]. Therefore, we evaluated the stability of the SA-PAH/PBA-PAH multilayer films in aqueous solutions with different $\mathrm{pH}$ values. Figure 6 presents the $-\triangle \mathrm{F}$ values determined for SA-PAH/PBA-PAH multilayer films at various $\mathrm{pH}$ values. Films were successfully prepared at $\mathrm{pH}$ values of 7.4 and 9.0 but not at $\mathrm{pH}$ 5. Under low $\mathrm{pH}$ conditions, bonding between the PBA and diols decreased and the formation of multilayer film was made more difficult $[37,38]$ as a result of the electrostatic repulsion between the SA-PAH and PBA-PAH.

Figure 7 summarizes the kinetics of the decomposition of the (SA-PAH/PBA-PAH) ${ }_{10}$ films in solutions with $\mathrm{pH}$ values of 5.0, 7.4 and 9.0. The percentage decomposition was estimated from the changes in the absorption intensity at $255 \mathrm{~nm}$. The films evidently decomposed rapidly at $\mathrm{pH}$ 5.0, presumably because the bonding between the PBA and diols decomposed under weakly acidic conditions. In contrast, the films were stable at $\mathrm{pH} 9.0$ for $3 \mathrm{~h}$, and only $10 \%$ decomposition was observed at $\mathrm{pH} 7.4$ over $3 \mathrm{~h}$. It should be noted that the evident stability at $\mathrm{pH} 7.4$ suggests that such films have potential applications in biomedical devices. Similar $\mathrm{pH}$-dependent stability has been reported for PVA/PBA-poly(amidoamine) dendrimer films [48]. 


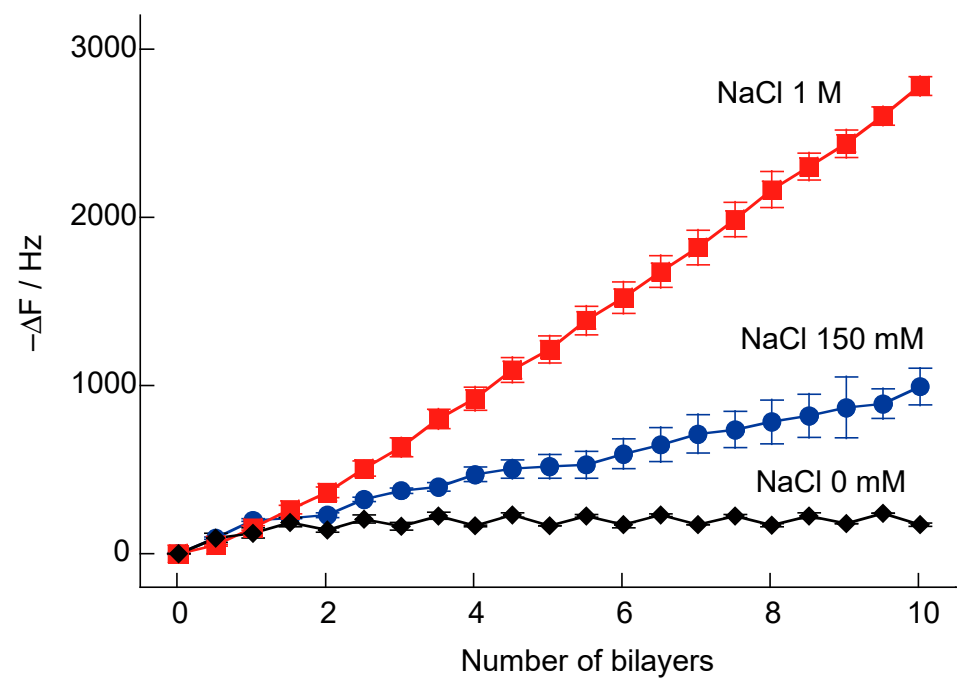

Figure 6. The effect of the $\mathrm{pH}$ value during the preparation of SA-PAH/PBA-PAH multilayer films in a 10 mM MES ( $\mathrm{pH}$ 5.0), 10 mM HEPES (pH 7.4) or 10 mM CHES buffer (pH 9.0). All buffer solutions contained $150 \mathrm{mM} \mathrm{NaCl}$.

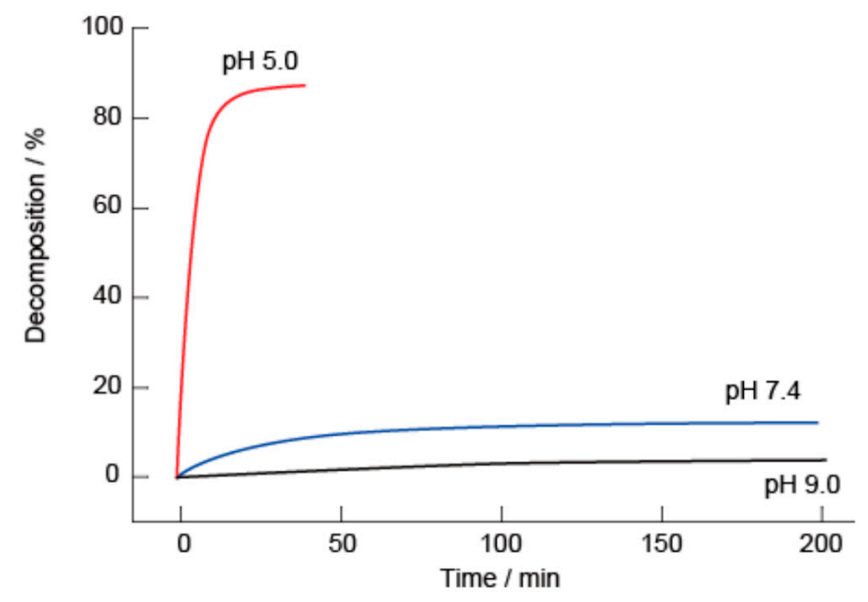

Figure 7. Decomposition kinetics of (SA-PAH/PBA-PAH) 10 films in $10 \mathrm{mM}$ MES (pH 5.0), $10 \mathrm{mM}$ HEPES ( $\mathrm{pH} 7.4$ ) or $10 \mathrm{mM}$ CHES ( $\mathrm{pH}$ 9.0) buffers. The films were prepared using a $10 \mathrm{mM}$ CHES buffer ( $\mathrm{pH}$ 9.0). All buffer solutions contained $1 \mathrm{M} \mathrm{NaCl}$.

Figure 8 presents the UV-vis absorption spectra of (SA-PAH/PBA-PAH) ${ }_{10}$ films before and after $60 \mathrm{~min}$ immersion in $1 \mathrm{mM} \mathrm{H}_{2} \mathrm{O}_{2}$. Due to PBA, the absorption intensity at $242 \mathrm{~nm}$ decreased markedly over time during this process. As shown in Figure 1, the carbon-boron bonds in PBA and boronate esters are oxidatively cleaved by $\mathrm{H}_{2} \mathrm{O}_{2}$, suggesting that the $\mathrm{H}_{2} \mathrm{O}_{2}$ induced the decomposition of the (SA-PAH/PBA-PAH $)_{10}$ films. The absorption at $290 \mathrm{~nm}$ also increases slightly over time in these spectra, due to the formation of phenol resulting from the oxidation of PBA.

The decomposition kinetics of the (SA-PAH/PBA-PAH) $)_{10}$ films in the presence of $\mathrm{H}_{2} \mathrm{O}_{2}$ was assessed by monitoring the adsorption intensity at $255 \mathrm{~nm}$ (Figure 9). This wavelength represents an isosbestic point for a combination of PBA-PAH and PBA-PAH during oxidation by $\mathrm{H}_{2} \mathrm{O}_{2}$. The (SA-PAH/PBA-PAH) ${ }_{10}$ film was found to decompose markedly in the presence of $\mathrm{H}_{2} \mathrm{O}_{2}$ and the rate of decomposition increased with increases in the $\mathrm{H}_{2} \mathrm{O}_{2}$ concentration. As an example, the decomposition percentages of films were determined to be $13 \%, 81 \%$ and $94 \%$ after 60,60 and $20 \mathrm{~min}$ in the presence of $0.1,1$ and $10 \mathrm{mM} \mathrm{H}_{2} \mathrm{O}_{2}$, respectively. 


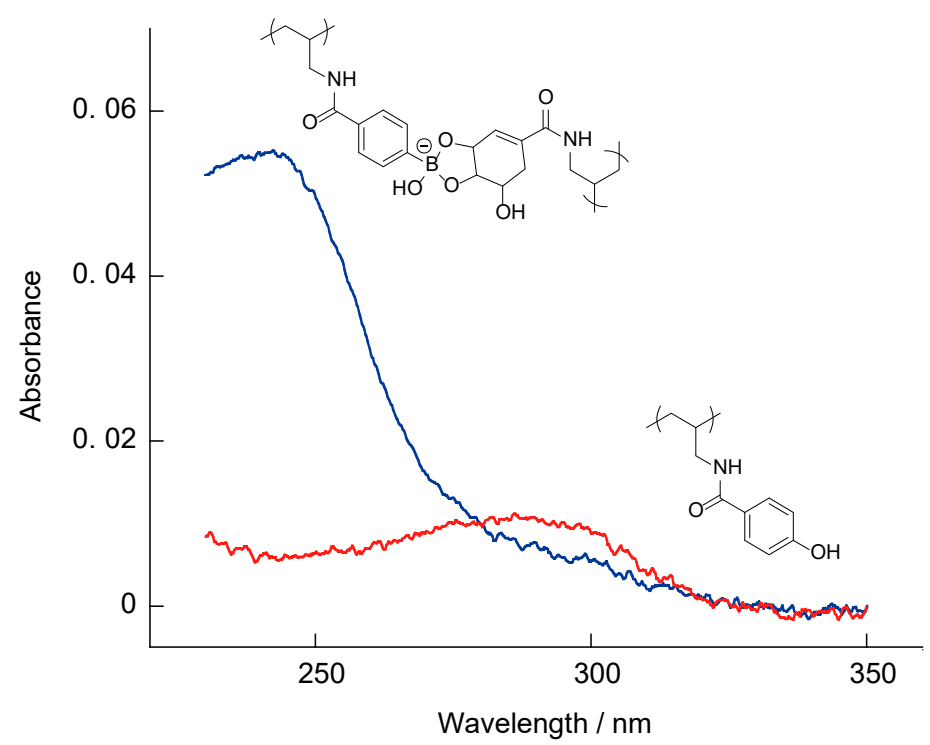

Figure 8. UV-vis absorption spectra of a (SA-PAH/PBA-PAH) $)_{10}$ film before (Blue line) and after $60 \mathrm{~min}$ immersion in $1 \mathrm{mM} \mathrm{H}_{2} \mathrm{O}_{2}$ (red line). The film was prepared in a $\left.10 \mathrm{mM} \mathrm{CHES} \mathrm{buffer} \mathrm{(} \mathrm{pH} 9.0\right)$ in the presence of $1 \mathrm{M} \mathrm{NaCl}$.

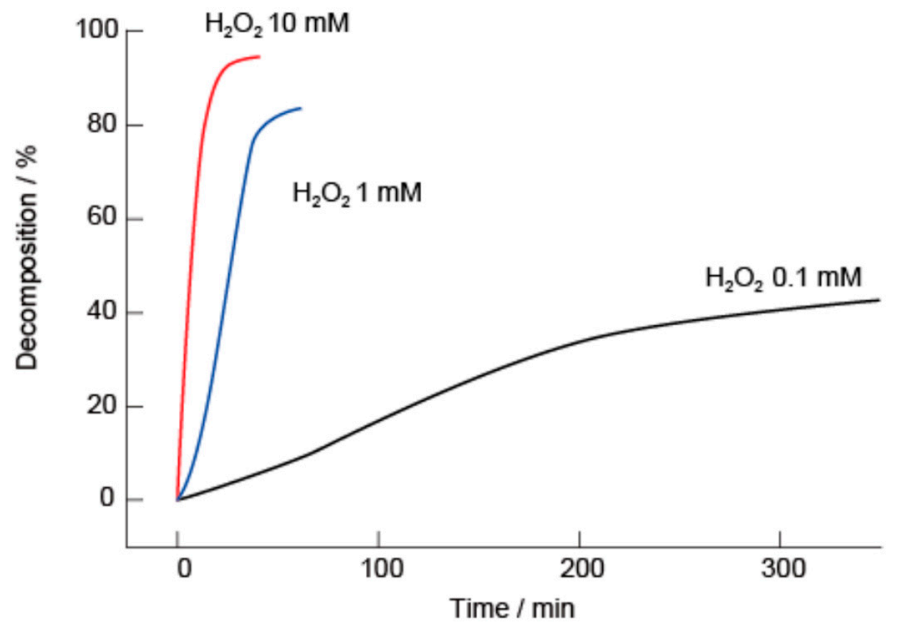

Figure 9. Decomposition kinetics of (SA-PAH/PBA-PAH) 10 films in the presence of $0.1,1$ and $10 \mathrm{mM}$ $\mathrm{H}_{2} \mathrm{O}_{2}$ in a $10 \mathrm{mM}$ CHES buffer ( $\mathrm{pH}$ 9.0). The films were prepared in a $10 \mathrm{mM} \mathrm{CHES} \mathrm{buffer} \mathrm{(} \mathrm{pH} 9.0$ ). All buffer solutions contained $1 \mathrm{M} \mathrm{NaCl}$.

A (SA-PAH/PBA-PAH) ${ }_{10}$ film was prepared on a quartz resonator modified with GOx to develop a glucose-responsive unit. GOx was adsorbed into the PAH layer and PBA-PAH layer via electrostatic interactions due to the negative charges present on the GOx at neutral $\mathrm{pH}$ (as a result of an isoelectric point of $\mathrm{pH}$ 4.2) [49]. The QCM data confirmed that an LbL film could be prepared on a GOx film (see Appendix A Figure A1). Table 1 summarizes the data related to the decomposition of $\mathrm{PAH} / \mathrm{GOx} /(\mathrm{SA}-\mathrm{PAH} / \mathrm{PBA}-\mathrm{PAH})_{10}$ films after immersion for $60 \mathrm{~min}$ in glucose solutions, based on $\Delta \mathrm{F}$ values obtained by QCM. These data demonstrate that the decomposition of the multilayer films was affected by the glucose concentration. The PAH/GOx/(SA-PAH/PBA-PAH) ${ }_{10}$ films were decomposed because GOx catalyzed the oxidation of D-glucose to generate $\mathrm{H}_{2} \mathrm{O}_{2}$ (Equation (1)).

$$
\text { D-glucose }+\mathrm{O}_{2} \rightarrow \text { D-glucono- } \delta \text {-lactose }+\mathrm{H}_{2} \mathrm{O}_{2}
$$


Table 1. The decomposition of $\mathrm{PAH} / \mathrm{GOx} /(\mathrm{SA}-\mathrm{PAH} / \mathrm{PBA}-\mathrm{PAH})_{10}$ films after immersion for $60 \mathrm{~min}$ in glucose solutions.

\begin{tabular}{cccc}
\hline \multirow{2}{*}{ Glucose } & pH 7.4 & pH 7.4 & pH 9.0 \\
\cline { 2 - 4 } & $\mathbf{N a C l} \mathbf{1 5 0} \mathbf{~ m M}$ & $\mathbf{N a C l ~ 1 ~ M ~}$ & $\mathbf{N a C l ~ 1 ~ M ~}$ \\
\hline $1 \mathrm{mM}$ & $16.9 \mathrm{~Hz}$ & $-2.9 \mathrm{~Hz}$ & $-18.9 \mathrm{~Hz}$ \\
$10 \mathrm{mM}$ & $34.6 \mathrm{~Hz}$ & $-8.6 \mathrm{~Hz}$ & $-25.8 \mathrm{~Hz}$ \\
$100 \mathrm{mM}$ & $43.8 \mathrm{~Hz}$ & $31.7 \mathrm{~Hz}$ & $-26.8 \mathrm{~Hz}$ \\
\hline
\end{tabular}

In contrast, two negative decomposition values were obtained in the presence of $1 \mathrm{M} \mathrm{NaCl}$ and the values were all negative when using $\mathrm{pH} 9.0$ and $1 \mathrm{mM} \mathrm{NaCl}$. These values are attributed to decreases in the GOx activity due to changes in the ionic strength and basicity of the solutions. Also, glucose was evidently adsorbed on the PBA in the films, thus actually increasing the film masses.

\subsection{Preparation of Microparticles Coated with SA-PAH/PBA-PAH Multilayer Films}

Microparticles coated with LbL films were obtained via the deposition of polymers on $\mathrm{CaCO}_{3}$ microparticles [46]. Figure 10 shows optical and fluorescence microscopy images of $\mathrm{PAH} / \mathrm{GOx} /(\mathrm{SA}-\mathrm{PAH} / \mathrm{PBA}-\mathrm{PAH})_{5}$ film-coated $\mathrm{CaCO}_{3}$ microparticles in which the PBA-PAH and GOx units have been labeled with fluorescein isothiocyanate (FITC) and tetramethylrhodamine isothiocyanate (TRITC). It is evident that there was no aggregation of the particles during the film deposition process, and that it was possible to apply multilayer films to the particles. The fluorescence images confirm that both PBA-PAH and GOx were deposited on the $\mathrm{CaCO}_{3}$.
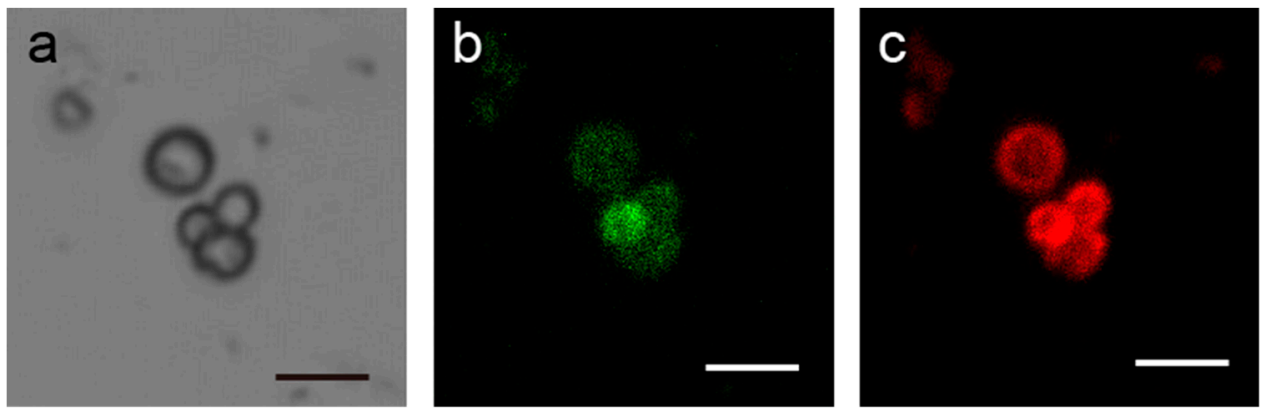

Figure 10. Optical microscopy (a) and fluorescence microscopy ((b), excitation: $488 \mathrm{~nm}$ ) and ((c) excitation: $543 \mathrm{~nm}$ ) images of $\mathrm{PAH} / \mathrm{GOx} /(\mathrm{SA}-\mathrm{PAH} / \mathrm{PBA}-\mathrm{PAH})_{5}$ film-coated $\mathrm{CaCO}_{3}$ microparticles in which PBA-PAH and GOx have been labeled with FITC and TRITC, respectively. The scale bar is $5 \mu \mathrm{m}$.

Figure 11 plots the absorbance at $255 \mathrm{~nm}$ following the $\mathrm{H}_{2} \mathrm{O}_{2}$-induced decomposition of (SA-PAH/PBA-PAH) $)_{5}$ film-coated $\mathrm{CaCO}_{3}$ microparticles. This wavelength represents the isosbestic point of PBA-PAH and PBA-PAH oxidized by $\mathrm{H}_{2} \mathrm{O}_{2}$. The absorbance values increased significantly in the presence of $\mathrm{H}_{2} \mathrm{O}_{2}$, with absorbance values of $0.027,0.082$ and 0.091 in conjunction with exposure to $\mathrm{H}_{2} \mathrm{O}_{2}$ concentrations of $0.1,1$ and $10 \mathrm{mM}$ for $1 \mathrm{~h}$. The increase in absorbance is derived from PBA-PAH oxidized by $\mathrm{H}_{2} \mathrm{O}_{2}$, which is a decomposition component of the (SA-PAH/PBA-PAH) 5 film on the $\mathrm{CaCO}_{3}$ microparticles. On the other hand, the multilayer films were not decomposed in the absence of $\mathrm{H}_{2} \mathrm{O}_{2}$. It was found that the SA-PAH/PBA-PAH multilayer film on $\mathrm{CaCO}_{3}$ microparticles decomposed in the presence of $\mathrm{H}_{2} \mathrm{O}_{2}$.

This work also developed microparticles capable of the glucose-induced release of insulin via the catalytic reaction of GOx under physiological conditions. Glucose-sensitive microparticles containing insulin were prepared by adsorbing DBD-insulin on multilayer films. Because insulin has a net negative charge at $\mathrm{pH} 7.4$ (as the isoelectric point of insulin is 5.4 [50]), it will be adsorbed on the PAH layer of the LbL film [51,52]. The glucose-induced decomposition of SA-PAH/PBA-PAH 
films would therefore be expected to release the insulin adsorbed on the microparticles. Figure 12 shows the DBD-insulin release from $1 \mathrm{mg}$ of PAH/GOx/(SA-PAH/PBA-PAH) 5 film-coated $\mathrm{CaCO}_{3}$ microparticles in glucose solutions of varying concentrations, as calculated from fluorescence intensities of DBD. The amounts of DBD-insulin released were determined to be $0.40,0.85$ and $2.32 \mu \mathrm{g}$ following the exposure of $\mathrm{CaCO}_{3}$ microparticles coated with $\mathrm{PAH} / \mathrm{GOx} /(\mathrm{SA}-\mathrm{PAH} / \mathrm{PBA}-\mathrm{PAH})_{5}$ films to 1, 10 and $100 \mathrm{mM}$ glucose solutions for $1 \mathrm{~h}$ at $\mathrm{pH}$ 7.4. DBD-insulin was also found to be released from $\mathrm{PAH} / \mathrm{GOx} /(\mathrm{SA}-\mathrm{PAH} / \mathrm{PBA}-\mathrm{PAH})_{5}$ film-coated $\mathrm{CaCO}_{3}$ microparticles in glucose solution, suggesting that the SA-PAH/PBA-PAH multilayer films on the $\mathrm{CaCO}_{3}$ were decomposed because GOx catalyzed the oxidation of D-glucose to generate $\mathrm{H}_{2} \mathrm{O}_{2}$. Once again, the amount of DBD-insulin released from the PAH/GOx/(SA-PAH/PBA-PAH $)_{5}$ film-coated $\mathrm{CaCO}_{3}$ microparticles increased with increasing glucose concentration. This process was superior in reactivity to the decomposition of the film under physiological conditions as compared with the method of glucose bound to PBA-PAH/PVA film to cleave the boronate ester bonds [36].

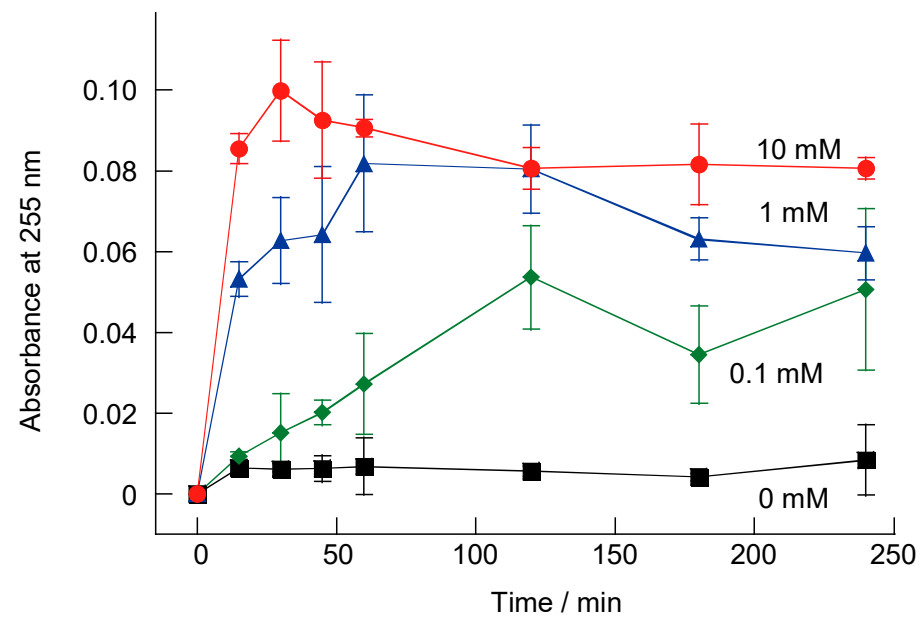

Figure 11. Absorbance at $255 \mathrm{~nm}$ resulting from the $\mathrm{H}_{2} \mathrm{O}_{2}$-induced decomposition of (SA-PAH/PBA-PAH) films on $\mathrm{CaCO}_{3}$ microparticles in a $10 \mathrm{mM}$ CHES buffer ( $\mathrm{pH} 9.0$ ) containing $1 \mathrm{M}$ $\mathrm{NaCl}$ in the presence of $0,0.1,1$ or $10 \mathrm{mM} \mathrm{H}_{2} \mathrm{O}_{2}$.

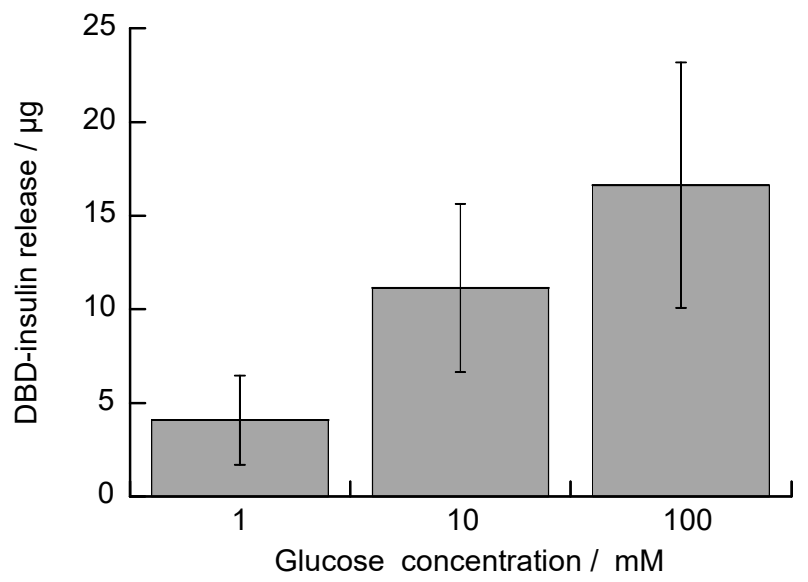

Figure 12. Amounts of DBD-insulin released from $1 \mathrm{mg}$ quantities of PAH/GOx/(SA-PAH/PBA-PAH) film-coated $\mathrm{CaCO}_{3}$ microparticles in a $10 \mathrm{mM}$ HEPES buffer $(\mathrm{pH} 7.4$, containing $150 \mathrm{mM} \mathrm{NaCl}$ ) in the presence of 1,10 or $100 \mathrm{mM}$ glucose. 


\section{Conclusions}

This work demonstrated that multilayer films can be constructed by the alternating deposition of SA-PBA and PBA-PAH, via the formation of boronate ester bonds. SA-PBA/PBA-PAH films were prepared at $\mathrm{pH} 7.4$ and $\mathrm{pH} 9$ in the presence of $\mathrm{NaCl}$. PAH/GOx/(SA-PBA/PBA-PAH $)_{\mathrm{n}}$ films were found to decompose in the presence of glucose due to oxidative scission of the carbon-boron bond of PBA-PAH by enzymatically-generated $\mathrm{H}_{2} \mathrm{O}_{2}$. All steps of the preparation and decomposition of PAH/GOx/(SA-PBA/PBA-PAH) ${ }_{n}$ films could be performed under physiological conditions. In addition, glucose-sensitive microparticles were fabricated by coating $\mathrm{CaCO}_{3}$ particles with $\mathrm{PAH} / \mathrm{GOx} /(\mathrm{SA}-\mathrm{PBA} / \mathrm{PBA}-\mathrm{PAH})_{5}$ films. Insulin pre-absorbed in the $\mathrm{PAH} / \mathrm{GOx} /(\mathrm{SA}-\mathrm{PAH} / \mathrm{PBA}-\mathrm{PAH})_{5}$ films was released following the addition of glucose, and the extent of release was dependent on the glucose concentration. Again, all steps of this process could be carried out under physiological conditions. These results demonstrate the potential application of microparticles that undergo glucose-induced decomposition in the development of insulin delivery systems. In insulin delivery systems, insulin loading microparticles remain stable at normal levels of blood glucose $(\sim 5 \mathrm{mM})$, and glucose-induced delivery microparticles that release insulin only when the blood glucose is higher than the diabetic level $(>10 \mathrm{mM})$ under physiological conditions are highly desirable [53]. Insulin release system depending on blood glucose will be realized by improving the suitable design of the film composition and the chemical structures of PBA-polymers.

Author Contributions: K.S. designed the work. K.Y., Y.K. and K.S. collected the materials. K.Y., K.A., S.S., M.I., Y.O. and M.I. were involved in the experimental works. Y.K., T.D., and T.O. helped drafting the article. The manuscript was prepared by K.Y and Y.K.

Funding: This work was supported by Grants-in-Aid for Scientific Research (numbers JP16K08189, JP18K06791 and JP18K19936) from the Japan Society for the Promotion of Science (JSPS).

Acknowledgments: This work was partially supported by JSPS KAKENHI grants (numbers JP16K08189, JP18K06791 and JP18K19936). The Ohu University Research Fund is also acknowledged for financial support.

Conflicts of Interest: The authors declare no conflicts of interest.

\section{Appendix A}

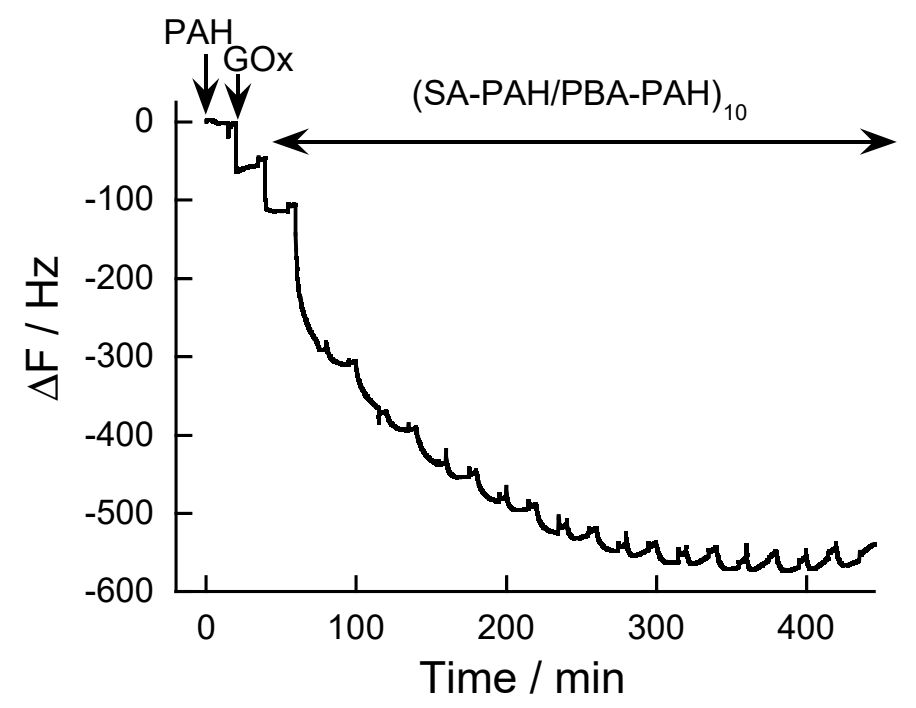

Figure A1. QCM resonator frequency changes during the preparation of a (PAH/GOx) (SA-PAH/PBA-PAH) 10 film in a 10 mM HEPES buffer (pH 7.4) in the presence of $150 \mathrm{mM} \mathrm{NaCl}$. 


\section{References}

1. Santini, J.T., Jr.; Cima, M.J.; Langer, R. A controlled-release microchip. Nature 1999, 397, 335-338. [CrossRef] [PubMed]

2. Wang, J.; Ye, Y.; Yu, J.; Kahkoska, A.R.; Zhang, X.; Wang, C.; Sun, W.; Corder, R.D.; Chen, Z.; Khan, S.A.; et al. Core-shell microneedle gel for self-regulated insulin delivery. ACS Nano 2008, 27, 2466-2473. [CrossRef] [PubMed]

3. Lim, H.P.; Tey, B.T.; Chan, E.S. Particle designs for the stabilization and controlled-delivery of protein drugs by biopolymers: A case study on insulin. J. Control. Release 2014, 186, 11-21. [CrossRef] [PubMed]

4. Donath, E.; Sukhorukov, G.B.; Caruso, F.; Davis, S.A.; Mohwald, H. Novel hollow polymer shells by colloid-templated assembly of polyelectrolytes. Angew. Chem. Int. Ed. Eng. 1998, 37, 2201-2205. [CrossRef]

5. Sundaramurthy, A.; Sundramoorthy, A.K. Polyelectrolyte capsules preloaded with interconnected alginate matrix: An effective capsule system for encapsulation and release of macromolecules. Int. J. Biol. Macromol. 2018, 107, 2251-2261. [CrossRef] [PubMed]

6. Yao, H.; Hu, N. pH-Switchable bioelectrocatalysis of hydrogen peroxide on layer-by-layer films assembled by concanavalin A and horseradish peroxidase with electroactive mediator in solution. J. Phys. Chem. B 2010, 114, 9926-9933. [CrossRef] [PubMed]

7. Qi, W.; Yan, X.; Fei, J.; Wang, A.; Cui, Y.; Li, J. Triggered release of insulin from glucose-sensitive enzyme multilayer shells. Biomaterials 2009, 30, 2799-2806. [CrossRef] [PubMed]

8. Chen, X.; Wu, W.; Guo, Z.; Xin, J.; Li, J. Controlled insulin release from glucose-sensitive self-assembled multilayer films based on 21-arm star polymer. Biomaterials 2011, 32, 1759-1766. [CrossRef] [PubMed]

9. Shiino, D.; Murata, Y.; Kubo, A.; Kim, Y.J.; Kataoka, K.; Koyama, Y.; Kikuchi, A.; Yokoyama, M.; Sakurai, Y.; Okano, T. Amine containing phenylboronic acid gel for glucose-responsive insulin release under physiological pH. J. Control. Release 1995, 37, 269-276. [CrossRef]

10. Mandal, D.; Mandal, S.K.; Ghosh, M.; Das, P.K. Phenylboronic acid appended pyrene-based low-molecular-weight injectable hydrogel: Glucose-stimulated insulin release. Chemistry 2015, 21, 12042-12052. [CrossRef] [PubMed]

11. Takei, C.; Ohno, Y.; Seki, T.; Miki, R.; Seki, T.; Egawa, Y. Sugar-responsive layer-by-layer film composed of phenylboronic acid-appended insulin and poly(vinyl alcohol). Chem. Pharm. Bull. 2018, 66, 368-374. [CrossRef] [PubMed]

12. Decher, G. Fuzzy Nanoassemblies: Toward layered polymeric multicomposites. Science 1997, 277, 1232-1237. [CrossRef]

13. Das, B.P.; Tsianou, M. From polyelectrolyte complexes to polyelectrolyte multilayers: Electrostatic assembly, nanostructure, dynamics, and functional properties. Adv. Colloid Interface Sci. 2017, 244, 71-89. [CrossRef] [PubMed]

14. Crouzier, T.; Boudou, T.; Picart, C. Polysaccharide-based polyelectrolyte multilayers. Curr. Opin. Colloid Interface Sci. 2010, 15, 417-426. [CrossRef]

15. Yoshida, K.; Sato, K.; Ono, T.; Dairaku, T.; Kashiwagi, Y. Preparation of nafion/polycation layer-by-layer films for adsorption and release of insulin. Polymers 2018, 10, 812. [CrossRef]

16. Yang, S.; Zhang, Y.; Guan, Y.; Tan, S.; Xu, J.; Cheng, S.; Zhang, X. Water uptake behavior of hydrogen-bonded PVPON-PAA LBL film. Soft Matter 2006, 2, 699-704. [CrossRef]

17. Sun, J.; Su, C.; Zhang, X.; Li, J.; Zhang, WB.; Zhao, N.; Xu, J.; Yang, S. Responsive complex capsules prepared with polymerization of dopamine, hydrogen-bonding assembly, and catechol dismutation. J. Colloid Interface Sci. 2018, 513, 470-479. [CrossRef] [PubMed]

18. Inoue, H.; Sato, K.; Anzai, J.-I. Disintegration of layer-by-layer assemblies composed of 2-iminobiotin-labeled poly(ethyleneimine) and avidin. Biomacromolecules 2005, 6, 27-29. [CrossRef] [PubMed]

19. Polak, R.; Crouzier, T.; Lim, R.M.; Ribbeck, K.; Beppu, M.M.; Pitombo, R.N.M.; Cohen, R.E.; Rubner, M.F. Sugar-mediated disassembly of mucin/lectin multilayers and their use as $\mathrm{pH}$-Tolerant, on-demand sacrificial layers. Biomacromolecules 2014, 15, 3093-3098. [CrossRef] [PubMed]

20. Kumarasamy, J.; Camarada, M.B.; Venkatraman, D.; Ju, H.; Dey, R.S.; Wen, Y. One-step coelectrodeposition-assisted layer-by-layer assembly of gold nanoparticles and reduced graphene oxide and its self-healing three-dimensional nanohybrid for an ultrasensitive DNA sensor. Nanoscale 2018, 3, 1196-1206. [CrossRef] [PubMed] 
21. Jang, E.; Son, K.J.; Koh, W. Metal-enhanced fluorescence using silver nanoparticles-embedded polyelectrolyte multilayer films for microarray-based immunoassays. Colloid Polym. Sci. 2014, 292, 1355-1364. [CrossRef]

22. Hoffman, K.; Tieke, B. Layer-by-layer assembled membranes containing hexacyclen-hexaacetic acid and polyethyleneimine $\mathrm{N}$-acetic acid and their ion selective permeation behavior. J. Membr. Sci. 2009, 341, 261-267. [CrossRef]

23. Huang, Z.; Li, M.; Li, N.; Tang, X.; Ouyang, Z. Antibacterial properties enhancement of layer-by-layer self-assembled nanofiltration membranes. J. Nanosci. Nanotechnol. 2018, 18, 4524-4533. [CrossRef] [PubMed]

24. Ribero, C.; Borges, J.; Costa, A.M.S.; Gaspar, V.M.; Bermudez, V.Z.; Mano, J.F. Preparation of well-dispersed chitosan/alginate hollow multilayered microcapsules for enhanced cellular internalization. Molecules 2018, 23, 625. [CrossRef] [PubMed]

25. Xu, W.; Ledin, P.A.; Iatridi, Z.; Tsitsilianis, C.; Tsukruk, V.V. Multicompartmental microcapsules with orthogonal programmable two-way sequencing of hydrophobic and hydrophilic cargo release. Angew. Chem. Int. Ed. 2016, 55, 4908-4913. [CrossRef] [PubMed]

26. Liu, P. Stabilization of layer-by-layer engineered multilayered hollow microspheres. Adv. Colloid Interface Sci. 2014, 207, 178-188. [CrossRef] [PubMed]

27. Yoshida, K.; Ono, T.; Kashiwagi, Y.; Takahashi, S.; Sato, K.; Anzai, J.-I. pH-dependent release of insulin from layer-by-layer-deposited polyelectrolyte microcapsules. Polymers 2015, 7, 1269-1278. [CrossRef]

28. Koker, S.D.; Hoogenboom, R.; De Geest, B.G. Polymeric multilayer capsules for drug delivery. Chem. Soc. Rev. 2012, 41, 2867-2884. [CrossRef] [PubMed]

29. Delcea, M.; Möhwald, H.; Skirtach, A.G. Stimuli-responsive LbL capsules and nanoshells for drug delivery. Adv. Drug Deilv. Rec. 2011, 63, 730-747. [CrossRef] [PubMed]

30. Anandhakumar, S.; Gokul, P.; Raichur, A.M. Stimuli-responsive weak polyelectrolyte multilayer films: A thin film platform for self triggered multi-drug delivery. Mater. Sci. Eng. C Mater. Biol. Appl. 2016, 58, 622-628. [CrossRef] [PubMed]

31. Dou, Y.; Han, J.; Wang, T.; Wei, M.; Evans, D.G.; Duan, X. Temperature-controlled electrochemical switch based on layered double hydroxide/poly( $N$-isopropylacrylamide) ultrathin films fabricated via layer-by-layer assembly. Langmuir 2012, 28, 9535-9542. [CrossRef] [PubMed]

32. Kim, B.A.; Gao, H.; Argun, A.A.; Matyjaszewski, K.; Hammond, P.T. All-star polymer multilayers as pH-responsive nanofilms. Macromolecules 2009, 42, 368-375. [CrossRef]

33. Ren, K.; Wang, Y.; Ji, J.; Lin, Q.; Shen, J. Construction and deconstruction of PLL/DNA multilayered films for DNA delivery: Effect of ionic strength. Colloids Surf. B Biointerfaces 2005, 46, 63-69. [CrossRef] [PubMed]

34. Zeng, G.; Xing, Y.; Gao, J.; Wang, Z.; Zhang, X. Unconventional layer-by-layer assembly of graphene multilayer films for enzyme-based glucose and maltose biosensing. Langmuir 2010, 26, 15022-15026. [CrossRef] [PubMed]

35. Mawad, D.; Molino, P.; Gambhir, G.; Loche, J.M.; Officer, D.L. Electrically induced disassembly of electroactive multilayer films fabricated from water soluble polythiophenes. Adv. Funct. Mater. 2012, 22, 5020-5027. [CrossRef]

36. Seno, M.; Yoshida, K.; Sato, K.; Anzai, J.-I. pH- and sugar-sensitive multilayer films composed of phenylboronic acid (PBA)-modified poly(allylamine hydrochloride) (PBA-PAH) and poly(vinyl alcohol) (PVA): A signigicant effect of PBA content on the film stability. Mater. Sci. Eng. C 2016, 62, 474-479. [CrossRef] [PubMed]

37. Yan, J.; Springsteen, G.; Deeter, S.; Wang, B. The relationship among $\mathrm{pKa}, \mathrm{pH}$, and binding constants in the interactions between boronic acids and diols-It is not as simple as it appears. Tetrahedron 2004, 60, 11205-11209. [CrossRef]

38. Springsteen, G.; Wang, B. A detailed examination of boronic acid-diol complexation. Tetrahedron 2002, 58, 5291-5300. [CrossRef]

39. Egawa, Y.; Miki, R.; Seki, T. Colorimetric sugar sensing using boronic acid-substituted azobenzenes. Materials 2014, 7, 1201-1220. [CrossRef] [PubMed]

40. Bull, S.D.; Davidson, M.G.; van den Elsen, J.M.H.; Fossey, J.S.; Jenkins, A.T.A.; Jiang, Y.; Kubo, Y.; Marken, F.; Sakurai, K.; Zhao, J.; et al. Exploiting the reversible covalent bonding of boronic acids: Recognition, sensing, and assembly. Acc. Chem. 2013, 46, 312-326. [CrossRef] [PubMed]

41. Ding, Z.; Guan, Y.; Zhang, Y.; Zhu, X.X. Layer-by-layer multilayer films linked with reversible boronate ester bonds with glucose-sensitivity under physiological conditions. Soft Matter 2009, 5, 2302-2309. [CrossRef] 
42. Sato, K.; Takahashi, S.; Anzai, J.-I. Layer-by-layer thin films and microcapsules for biosensors and controlled release. Anal. Sci. 2012, 28, 929-938. [CrossRef] [PubMed]

43. Simon, J.; Salzbrunn, S.; Prakash, G.K.S.; Petasis, N.A.; Olah, G.A. Regioselective conversion of arylboronic acids to phenols and subsequent coupling to symmetrical diaryl ethers. J. Org. Chem. 2001, 66, 633-634. [CrossRef] [PubMed]

44. Sato, K.; Takahashi, M.; Ito, M.; Abe, E.; Anzai, J.-I. $\mathrm{H}_{2} \mathrm{O}_{2}$-induced decomposition of layer-by-layer films consisting of phenylboronic acid-bearing poly(allylamine) and poly(vinyl alcohol). Langmuir 2014, 30, 9247-9250. [CrossRef] [PubMed]

45. Sato, K.; Takahashi, M.; Ito, M.; Abe, E.; Anzai, J.-I. Glucose-induced decomposition of layer-by-layer films composed of phenylboronic acid-bearing poly(allylamine) and poly(vinyl alcohol) under physiological conditions. J. Mater. Chem. B 2015, 3, 7796-7802. [CrossRef]

46. Tong, W.; Dong, W.; Ga, C.; Mohwald, H. Multilayer capsules with cell-like topology: Fabrication and spontaneous loading of various substances in aqueous and ethanol solutions. Macromol. Chem. Phys. 2005, 206, 1784-1790. [CrossRef]

47. Kolasińska, M.; Warszyński, P. The effect of support material and conditioning on wettability of PAH/PSS multilayer films. Bioelectrochemistry 2005, 66, 65-70. [CrossRef] [PubMed]

48. Suwa, K.; Nagasaka, M.; Niina, S.; Egawa, Y.; Seki, T.; Anzai, J.-I. Sugar response of layer-by-layer films composed of poly(vinyl alcohol) and poly(amidoamine) dendrimer bearing 4-carboxyphenylboronic acid. Colloid Polym. Sci. 2015, 293, 1043-1048. [CrossRef]

49. Sato, K.; Abe, E.; Takahashi, M.; Anzai, J.-I. Loading and release of fluorescent dye from layer-by-layer film-coated magnetic particles in response to hydrogen peroxide. J. Colloid Interface Sci. 2014, 432, 92-97. [CrossRef] [PubMed]

50. Cui, F.; Shi, K.; Zhang, L.; Tao, A. Biodegradable nanoparticles loaded with insulin-phospholipid complex for oral delivery: Preparation, in vitro characterization and in vivo evaluation. J. Control. Release 2006, 114, 242-250. [CrossRef] [PubMed]

51. Yoshida, K.; Hashide, R.; Ishii, T.; Takahashi, S.; Sato, K.; Anzai, J.-I. Layer-by-layer films composed of poly(allylamine) and insulin for $\mathrm{pH}$-triggered release of insulin. Colloid Surf. B 2012, 91, 274-279. [CrossRef] [PubMed]

52. Hashide, R.; Yoshida, K.; Hasebe, Y.; Takahashi, S.; Sato, K.; Anzai, J.-I. Insulin-containing layer-by-layer films deposited on poly(lactic acid) microbeads for $\mathrm{pH}$-controlled release of insulin. Colloid Surf. B 2012, 89, 242-247. [CrossRef] [PubMed]

53. Wang, B.; Yoshida, K.; Sato, K.; Anzai, J.-I. Phenylboronic acid-finctionalized layer-by-layer assemblies for biomedical applications. Polymers 2017, 9, 202. [CrossRef] 